\title{
Regulation of the microvascular circulation in the leg muscles, pancreas and small intestine in rats
}

\author{
Hisashi Maeda ${ }^{1}$,Tomoyuki Kurose ${ }^{2}$ and Seiichi Kawamata ${ }^{2 *}$
}

\begin{abstract}
To study the microvascular circulation, we examined the proportion of open and functioning capillaries in the leg muscles, pancreas and small intestine of anesthetized rats. Fluorescein isothiocyanate (FITC)-labeled Lycopersicon esculentum lectin was injected into the heart and allowed to circulate for 3 min to label open and functioning capillaries. Specimens were removed, frozen, sectioned and double-immunostained. Using one section, open and functioning capillaries were detected by immunostaining for this lectin bound to endothelial cells, while all capillaries were visualized by immunostaining for platelet endothelial cell adhesion molecule-1 (PECAM-1 or CD31). These capillaries were semi-automatically detected and counted by fluorescence microscopy. The percentages of open and functioning capillaries were as follows: the soleus muscle, $93.0 \pm 5.5 \%$; superficial zone of the gastrocnemius muscle, $90.8 \pm 6.2 \%$; deep zone of the gastrocnemius muscle, $95.6 \pm 4.0 \%$; the plantaris muscle, $94.1 \pm 2.7 \%$; the pancreas, $86.3 \pm 11.7 \%$; and the small intestine, $91.1 \pm 4.9 \%$ ( $n=8$, each). There was no significant difference among these data by the Kruskal-Wallis test. This study clearly demonstrated that the proportions of open and functioning capillaries are high and similar among the leg muscles, pancreas and small intestine in spite of their structural and functional differences. This finding agrees with previous studies and supports the notion that the microvascular circulation is mainly controlled by changing of the blood flow in each capillary rather than changing the proportion of open and functioning capillaries.
\end{abstract}

Keywords: Capillary, Blood flow, Lycopersicon esculentum lectin, PECAM-1 (platelet endothelial cell adhesion molecule-1), CD31, Immunohistochemistry

\section{Background}

The blood supply is vitally important for the transport of essential materials and metabolic waste. Capillaries are densely distributed throughout most tissues and organs. Adapting to physiological conditions, the microvascular circulation is elaborately regulated. For example, blood flow of skeletal muscles is low at rest, but drastically increases upon exercise (Nilsson and Ingvar 1967; Terjung and Engbretson 1988; Musch and Terrell 1992; Hawker and Egginton 1999; Kindig et al. 2002; Richardson et al. 2003) and local warming (Edholm et al. 1956;

\footnotetext{
*Correspondence: kawamat@hiroshima-u.ac.jp

2 Department of Anatomy and Histology, Institute of Biomedical and Health Sciences, Hiroshima University, Kasumi 1-2-3, Minami-ku, Hiroshima 734-8551, Japan

Full list of author information is available at the end of the article
}

Minson et al. 2001; Fiscus et al. 2005). Furthermore, blood flow in various tissues and organs is significantly different. The blood flow of rat per unit time and weight is reported as follows (Musch and Terrell 1992): the soleus muscle, $140 \pm 18$; superficial zone of the gastrocnemius muscle (gastrocnemius, white), $10 \pm 2$; deep zone of the gastrocnemius muscle (gastrocnemius, red), $60 \pm 12$; the plantaris muscle, $15 \pm 3$; the pancreas, $148 \pm 22$; and the small intestine, $247 \pm 29 \mathrm{ml} \mathrm{min}^{-1} 100 \mathrm{~g}^{-1}$ (mean $\pm \mathrm{SE}$ ). However, the regulation mechanism of blood flow in the capillary bed is not fully understood.

The blood flow considerably changes depending on the blood flow velocity (Honig et al. 1980; Richardson et al. 2003) and the size of blood vessels (Kano et al. 2005). These factors are influenced by the blood pressure, nerve activity (Minson et al. 2001; Johnson et al. 2005),

\section{望 Springer}


vasoactive substances (Minson et al. 2001; Koganezawa et al. 2006), blood viscosity, contraction of the skeletal muscle (Nilsson and Ingvar 1967), tissue temperature (Karunakara et al. 1999; Koganezawa et al. 2006; Keller et al. 2010) and so on. The proportion of open and functioning capillaries, i.e., the percentage of capillaries supporting continuous red blood cell flow (Kindig et al. 2002), is also assumed to influence blood flow. If nonflowing capillaries in resting muscle are recruited during muscle contraction, the proportion of open and functioning capillaries will increase (Honig et al. 1980), resulting in an increase of blood flow. On the other hand, Poole et al. (2013) stated that the majority of capillaries support blood flow at rest and are not available to be recruited. The proportion of open and functioning capillaries has been repeatedly measured in skeletal muscles (Renkin et al. 1981; Kayar and Banchero 1985; Kindig et al. 2002; Kano et al. 2005; Maeda et al. 2014) and remains controversial (Poole 2014; Barrett et al. 2014).

Concerning microvascular studies, Lycopersicon esculentum lectin is well known to bind endothelial cells and has been employed in combination with PECAM-1 immunostaining (Hashizume et al. 2000; Morikawa et al. 2002; Inai et al. 2004; Mazzetti et al. 2004; NakamuraIshizu et al. 2008; Maeda et al. 2014; Robertson et al. 2015). In this method, the plasma flow results in lectin binding to endothelial cells, even without moving red blood cells. However, Kawaguchi et al. (2012) observed similar spatiotemporal behaviors for the plasma and red blood cells, being labeled by water-soluble Qdot and fluorescein isothiocyanate (FITC), respectively. Poole et al. (2013) found that the majority of capillaries support blood flow in resting muscle, although plasma and red blood cells travel at different speeds through capillaries. Thus, it is plausible that plasma and red blood cells flow through open and functioning capillaries in most capillaries.

In our previous study, two serial cross sections were used to measure the proportion of open and functioning capillaries in rat leg muscles (Maeda et al. 2014). In paired cross sections of skeletal muscles, the number, location and direction of blood vessels are almost the same since most blood vessels run along the muscle fiber's long axis. In the majority of tissues and organs, however, blood vessels run in various directions and the profile of the capillary bed considerably differs between two adjacent sections. Then, we employed a double-immunostaining method that uses only one section instead of using two adjacent sections. This method can be used for not only skeletal muscles but also organs containing randomly oriented capillaries. In the present study, we measured the proportion of open and functioning capillaries in leg muscles as a muscle tissue, the pancreas as an example of a parenchymal organ and the small intestine as an example of a luminal organ, and examined whether or not these data differ among these tissues and organs, reflecting their structural and functional differences.

\section{Results}

All specimens were clearly stained by immunostaining. The semi-automatic counting system in the present study needs much less time for measurements with minimal observer bias (Figure 1). The percentages of open and functioning capillaries were as follows: the soleus muscle, $93.0 \pm 5.5 \%$ (Figure 2); the superficial zone of the gastrocnemius muscle, $90.8 \pm 6.2 \%$; the deep zone of the gastrocnemius muscle, $95.6 \pm 4.0 \%$; the plantaris muscle, $94.1 \pm 2.7 \%$; the pancreas, $86.3 \pm 11.7 \%$; and the small intestine, $91.1 \pm 4.9 \%(\mathrm{n}=8$, each) (Figure 3). These values were not significantly different from each other by the Kruskal-Wallis test (Figure 4).

\section{Discussion}

In the present study, the proportion of open and functioning capillaries was semi-automatically measured using one section after double immunostaining. The results for skeletal muscles were generally in agreement with previous studies (Kayar and Banchero 1985; Kindig et al. 2002; Kano et al. 2005; Maeda et al. 2014). The proportions of open and functioning capillaries of skeletal muscles, pancreas and small intestine were high and not significantly different, in spite of their structural and functional differences. Our finding seems to support the notion that microvascular blood flow in various tissues and organs is mainly controlled by regulating the blood flow of each capillary, while the proportion of open and functioning capillaries remains relatively constant (Kindig et al. 2002; Maeda et al. 2014).

\section{Advantages of double-immunostaining of one section}

In the case of skeletal muscle, most capillaries run along the long axis of muscle fibers. Thus, the profiles of the capillary bed are quite similar in serial cross sections. On the other hand, capillaries of the pancreas and small intestine run in various directions so the number, location and direction of capillaries can considerably differ from one section to another. Thus, the pancreas and small intestine were difficult to evaluate in terms of the proportion of open and functioning capillaries using paired sections. In the present study, however, L. esculentum lectin and PECAM-1 were sequentially stained in the same section. This method enabled us to examine various tissues and organs that have randomly oriented capillaries. In addition, the data of this method are probably more accurate and reliable than when measured by manual counting using paired sections stained for $L$. 


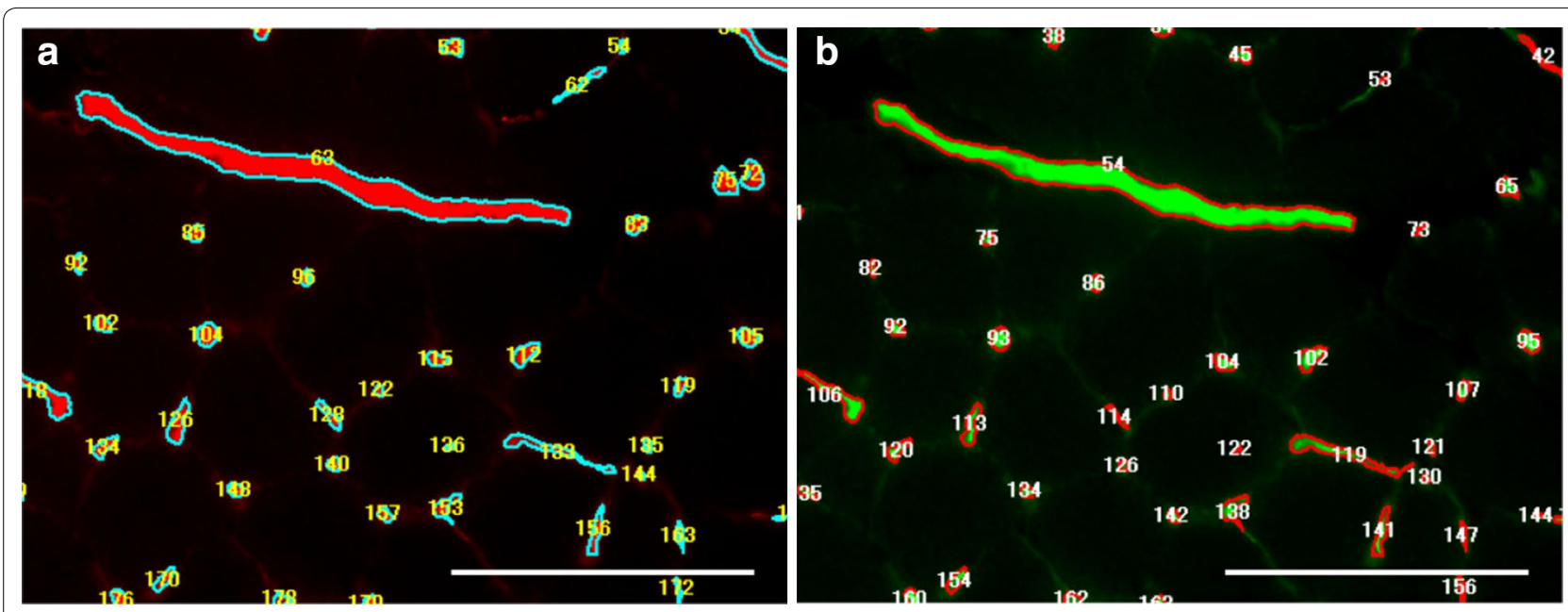

Figure 1 Semi-automatic counting of capillaries (an upper part of Figure 2a, b). Texas Red-positive (a) and FITC-positive (b) capillaries in the same field of a soleus muscle were automatically detected, numbered and counted after fine adjustment of threshold of the software. Bars $100 \mu \mathrm{m}$.

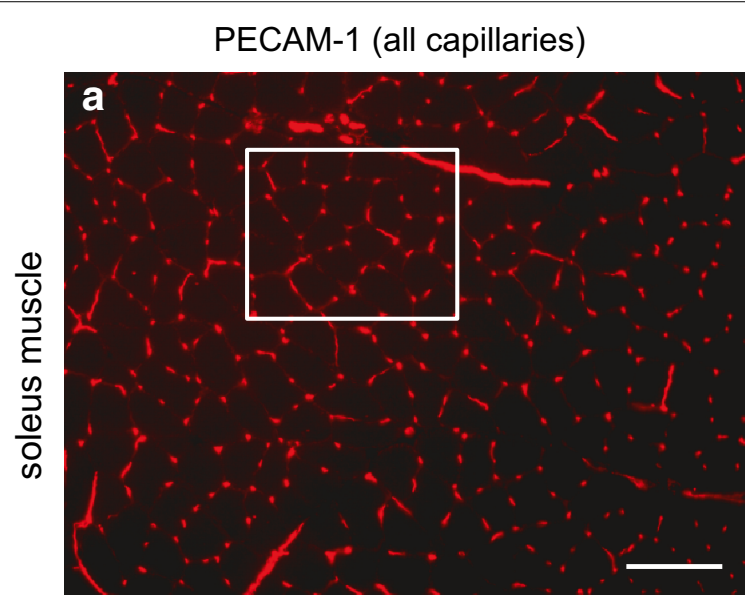

\section{Lectin (open and functioning capillaries)}

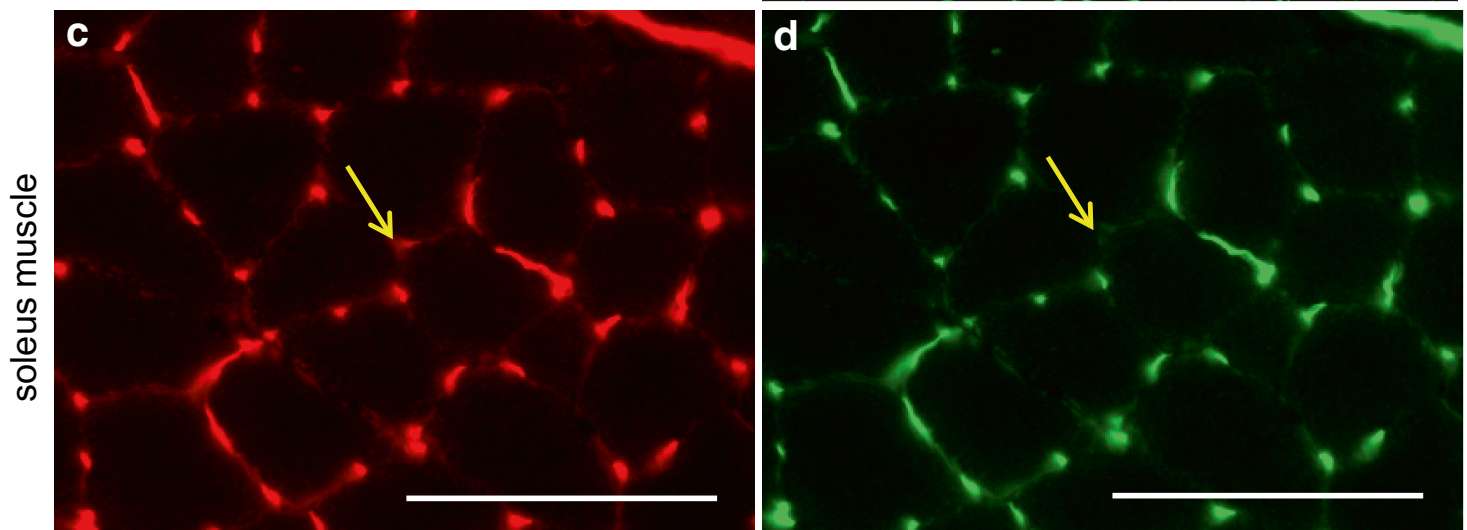

Figure 2 Micrographs of the soleus muscle. Panels a and $\mathbf{c}$ show staining for PECAM-1 (red) to detect all capillaries. Panels $\mathbf{b}$ and $\mathbf{d}$ show staining for FITC-lectin (green) to detect open and functioning capillaries. Panels $\mathbf{c}$ and $\mathbf{d}$ are higher magnification of rectangles in panels $\mathbf{a}$ and $\mathbf{b}$, respectively. Most capillaries are FITC-lectin positive. No blood flow is observable in a capillary (arrows). Bars 100 m. 


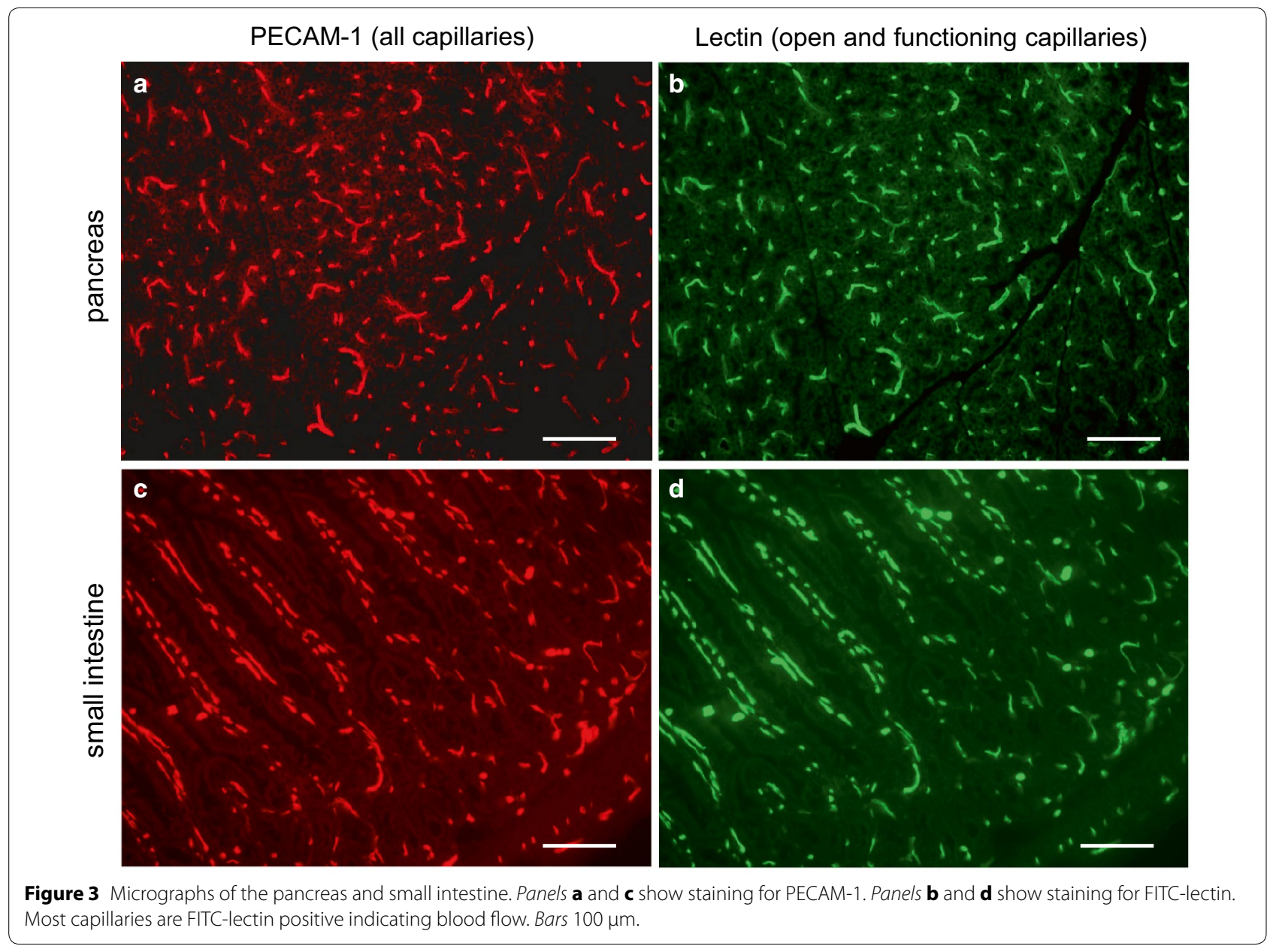

esculentum lectin and PECAM-1 separately in skeletal muscles (Maeda et al. 2014).

It is reported that anti-PECAM-1 antibody weakly stains lymphatic vessels (Ebata et al. 2001). Although there are lymphatic vessels (lacteals) in the villi of the small intestine, the proportion of open and functioning capillaries in the small intestine was almost comparable to those in the leg muscles and pancreas. This finding may indicate that lymphatic vessels do not interfere with measurements.

\section{Regulation of capillary blood flow}

Capillary blood flow is influenced by blood flow velocity, diameter of blood vessels, and possibly systemic blood pressure. The velocity of muscle blood flow is considerably different from one capillary to another (Smaje et al. 1970), even at rest, and the velocity of blood flow drastically increases during muscle contraction (Honig et al. 1980; Kindig et al. 2002; Richardson et al. 2003). Furthermore, blood vessels dilate by axonal reflex and NO production by local heating (Minson et al. 2001). On the other hand, the arterioles are responsible for the vasoconstriction and a decrease of the velocity of blood flow (Lindbom et al. 1980).

Concerning the blood pressure, pentobarbital anesthesia $(40 \mathrm{mg} / \mathrm{kg}$ ) is reported to depress systemic blood pressure $(91 \mathrm{mmHg}$, Field et al. 1993; $104 \pm 2 \mathrm{mmHg}$, Kindig et al. 2002) compared with control rats $(128 \mathrm{mmHg}$, Field et al. 1993). A decrease of the systemic blood pressure can lead to a reduction of the proportion of open and functioning capillaries; however, our results were high. Thus, it seems unlikely that pentobarbital anesthesia greatly changed the proportion of open and functioning capillaries.

The present study demonstrated that the proportions of open and functioning capillaries are high and similar in spite of structural and functional differences. This finding is in good agreement with the model proposed by Poole et al. (2013) and suggests that the microvascular systems of tissues and organs seem to share blood supply rather than a complete on-off capillary system. There is increasing evidence that most capillaries support blood 


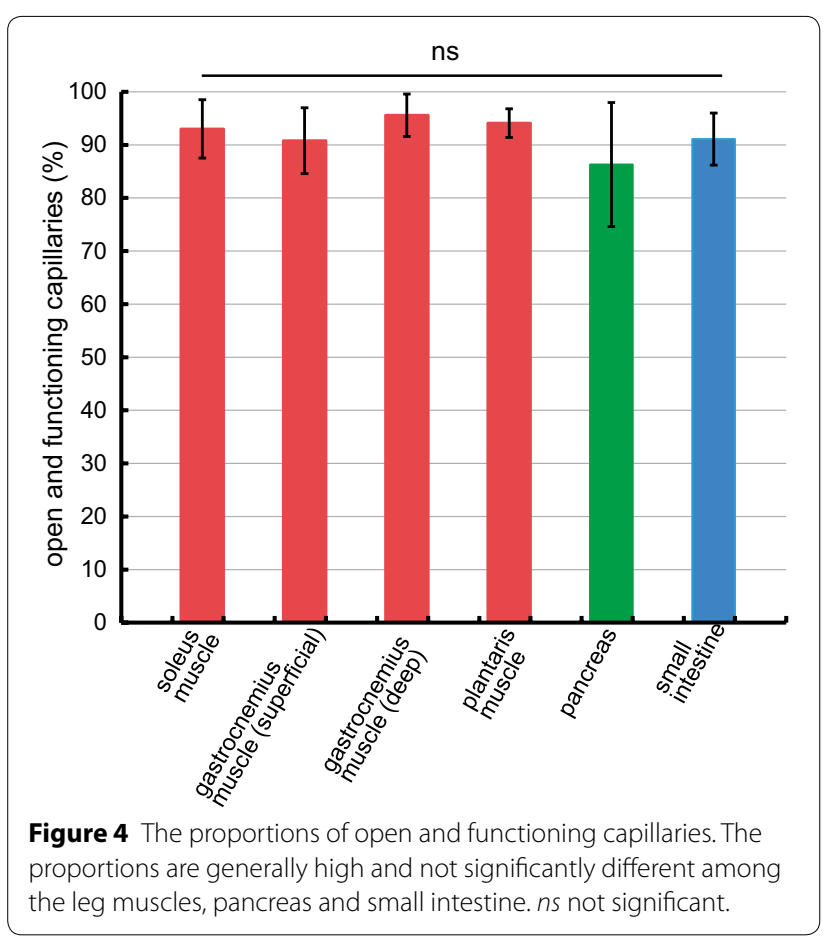

flow in resting muscle and that precapillary sphincters are unlikely to exist except for the mesenteric microcirculation (Lindbom et al. 1980; Sakai and Hosoyamada 2013). Thus, the mechanism controlling the microvascular system needs to be clarified further.

\section{Conclusions}

Considerable differences were reported in the blood flow in the leg muscle, pancreas and small intestine; however, the proportions of open and functioning capillaries were not significantly different in the present study. This finding indicates that the microvascular circulation in various tissues and organs is mainly controlled by changing of the blood flow in each capillary in spite of structural and functional differences, while the proportion of open and functioning capillaries was essentially unchanged.

\section{Methods}

The present experimental procedures were approved by the Committee of Research Facilities for Laboratory Animal Science, Hiroshima University.

A total of eight Wistar male rats $(254.6 \pm 7.9 \mathrm{~g}$, mean \pm SD) aged 8 weeks old were used. The rats were anesthetized by an intraperitoneal injection of sodium pentobarbital $(50 \mathrm{mg} / \mathrm{kg})$ assisted by the inhalation of diethyl ether when necessary. The temperature of the right leg was monitored using a needle-type thermometer, TL3633 (25 mm long, diameter $1.3 \mathrm{~mm}$; As One, Osaka, Japan), inserted into the hypodermis along the tibia. After tracheotomy and insertion of a breathing tube, mechanical ventilation was started and the left thorax was opened to expose the heart. A diluted solution of $200 \mu \mathrm{g} / 200 \mu \mathrm{l}$ of FITC-labeled L. esculentum lectin (diluted 1:1 with saline, Vector, Burlingame, CA, USA) was injected into the bloodstream via the heart, mixed with blood and allowed to circulate in the whole body. This lectin is known to bind to vascular endothelium (Hashizume et al. 2000; Mazzetti et al. 2004) and 2-10 min was allowed for labeling blood vessels (Hashizume et al. 2000; Morikawa et al. 2002; Inai et al. 2004; Nakamura-Ishizu et al. 2008). Three minutes after the lectin injection, the heart was clamped using a hemostat to stop the blood flow. The right leg was maintained within $37.0 \pm 0.8^{\circ} \mathrm{C}$ by cooling or warming during the period of lectin circulation. Recorded rectal temperature was within $37.0 \pm 0.7^{\circ} \mathrm{C}$. The soleus, gastrocnemius, plantaris muscles, pancreas and small intestine (presumably the jejunum) were removed. Muscles were transversally cut into three pieces and mid-belly portions were used. Muscles were aligned so that cross sections were cut and adhered to a piece of balsa wood (1 mm thick) that had been prefixed using glue at a right angle on a cork disk and coated with $6 \%$ tragacanth gum jelly just before use. The specimen and balsa wood on a cork disk were further supported with $6 \%$ tragacanth gum jelly and rapidly frozen in isopentane cooled with liquid nitrogen. The lumen of the small intestine was flushed with saline using a syringe and a tube. The small intestine and pancreas were half-embedded in $6 \%$ tragacanth gum jelly on cork disks and rapidly frozen. Cryosections (10 $\mu \mathrm{m}$ thick) were cut for immunostaining.

\section{Double-immunostaining}

Cryosections were air-dried, rinsed three times for $5 \mathrm{~min}$ each to remove free FITC-lectin in $0.01 \mathrm{M}$ phosphate-buffered saline (PBS, pH 7.2), fixed in cold acetone for $10 \mathrm{~min}$ and rinsed in PBS once for $5 \mathrm{~min}$. Nonspecific binding sites were blocked for $30 \mathrm{~min}$ with a blocking solution containing $1 \%$ normal rabbit serum in PBS for FITC-lectin immunostaining. After blotting the blocking solution, the sections were incubated with a sheep anti-FITC antibody (1:500; Southern Biotech, Birmingham, AL, USA) for $2 \mathrm{~h}$. Sections were rinsed with PBS three times for $5 \mathrm{~min}$ each and incubated for $1 \mathrm{~h}$ with rabbit biotinylated anti-sheep IgG antibody (1:100; Vector). Then, the sections were rinsed with PBS twice for $5 \mathrm{~min}$ each and incubated with FITC-labeled avidin (1:1,000; Vector) for $30 \mathrm{~min}$. After two rinses with PBS for 5 min each, sections were treated with PBS containing 1\% normal horse serum for 30 min for blocking of PECAM-1 immunostaining. After blotting, the sections were incubated with 
a mouse anti-PECAM-1 antibody (1:50; clone TLD3A12, BD Bioscience, San Diego, CA, USA) for $2 \mathrm{~h}$. Sections were rinsed with PBS three times for $5 \mathrm{~min}$ each and incubated for $1 \mathrm{~h}$ with horse biotinylated anti-mouse IgG antibody (1:100; Vector). Then, sections were rinsed with PBS twice for $5 \mathrm{~min}$ each and incubated with Texas Red-labeled avidin (1:50; Vector) for $30 \mathrm{~min}$. After two rinses with PBS for 5 min each, sections were mounted with Vectashield (Vector). All procedures were conducted at room temperature. Sections skipping incubation with the primary antibody were all negative except for weak intrinsic fluorescence from FITC-labeled L. esculentum lectin. This weak fluorescence was unlikely to affect measurement because injected lectin was small in quantity. When $25 \mu \mathrm{g}$ of FITC-labeled L. esculentum lectin was intravenously injected into a mouse, the liver was only lightly labeled (Robertson et al. 2015). In addition, fluorescence was much enhanced by immunostaining and the threshold of measurement was adjusted as described below.

\section{Calculation of the proportion of open and functioning capillaries}

The center of each section of the soleus and plantaris muscles was photographed using a fluorescence microscope, Biorevo BZ-9000 (Keyence, Osaka, Japan), at a total magnification of 200. The gastrocnemius muscle was photographed at both superficial and deep zones separately because muscle fiber composition and capillary density differ between these zones. Each field was photographed twice: first with a filter set for FITC, and second with a filter set for Texas Red. Displaying these photographs on a computer display, one representative capillary that was clearly stained for both Texas Red and FITC was selected in each field. The number of pixels of the Texas Red-positive area of the selected capillary was measured using the software BZ II (Keyence) installed in the microscope system. Next, the number of pixels of the FITC-positive area of the selected capillary was measured. Then, the threshold of the software was adjusted so that the number of pixels of the FITC-positive area of the selected capillary approached the number of pixels of the Texas Red-positive area of the capillary as closely as possible. Using the software BZ II, Texas Red-positive areas (all capillaries) and FITC-positive areas (open and functioning capillaries), regardless of longitudinal or cross sections of capillaries, were automatically detected, numbered and counted (Figure 1). At least 170 (range 170-554) capillaries were examined in each specimen. To calculate the proportion of open and functioning capillaries, the number of FITC-positive areas was divided by the number of Texas Red-positive areas and multiplied by 100 .

\section{Statistical analysis}

All data are presented as mean $\pm \mathrm{SD}$. Data distribution was assessed via the Shapiro-Wilk test for normality. To test whether the samples were from populations with equal variances, Bartlett's test was used. Because normality and dispersion were not equal, the Kruskal-Wallis test was used. A statistical significance level of $p<0.05$ was accepted.

\section{Authors' contributions}

All authors participated to conduct experiments and prepare specimens. HM and TK sectioned and carried out immunostaining. HM and TK also photographed, measured and analyzed data. HM and SK drafted the manuscript. All authors read and approved the final manuscript.

\section{Author details}

${ }^{1}$ Graduate School of Biomedical and Health Sciences, Hiroshima University, Kasumi 1-2-3, Minami-ku, Hiroshima 734-8551, Japan. ${ }^{2}$ Department of Anatomy and Histology, Institute of Biomedical and Health Sciences, Hiroshima University, Kasumi 1-2-3, Minami-ku, Hiroshima 734-8551, Japan.

\section{Acknowledgements}

We thank N. Shinnosuke and H. Yamanouchi for excellent technical support.

\section{Compliance with ethical guidelines}

\section{Competing interests}

The authors declare that they have no competing interest.

Received: 25 March 2015 Accepted: 15 June 2015

Published online: 26 June 2015

\section{References}

Barrett EJ, Keske MA, Rattigan S, Eringa EC (2014) CrossTalk proposal: De nove capillary recruitment in healthy muscle is necessary. J Physiol 592(PT23):5129-5131. doi:10.1113/jphysiol.2014.282137

Ebata N, Sawa Y, Nodasaka Y, Yamaoka Y, Yoshida S, Totsuka Y (2001) Immunoelectron microscopic study of PECAM-1 expression on lymphatic endothelium of the human tongue. Tissue Cell 33(3):211-218

Edholm OG, Fox RH, Macpherson RK (1956) The effect of body heating on the circulation in skin and muscle. J Physiol 134(3):612-619

Field KJ, White WJ, Lang CM (1993) Anaesthetic effects of chloral hydrate, pentobarbitone and urethane in adult male rats. Lab Anim 27(39):258-269

Fiscus KA, Kaminski TW, Powers ME (2005) Changes in lower-leg blood flow during warm-, cold-, and contrast-water therapy. Arch Phys Med Rehabil 86(7):1404-1410

Hashizume H, Baluk P, Morikawa S, McLean JW, Thurston G, Roberge S et al (2000) Openings between defective endothelial cells explain tumor vessel leakiness. Am J Pathol 156(4):1363-1380

Hawker MJ, Egginton S (1999) The effect of stimulation frequency on blood flow in rat fast skeletal muscles. Exp Physiol 84(5):941-946

Honig CR, Odoroff CL, Frierson JL (1980) Capillary recruitment in exercise: rate, extent, uniformity, and relation to blood flow. Am J Physiol 238(1): $\mathrm{H} 31-\mathrm{H} 42$

Inai T, Mancuso M, Hashizume H, Baffert F, Haskell A, Baluk P et al (2004) Inhibition of vascular endothelial growth factor (VEGF) signaling in cancer causes loss of endothelial fenestrations, regression of tumor vessels, and appearance of basement membrane ghosts. Am J Pathol 165(1):35-52

Johnson JM, Yen TC, Zhao K, Kosiba WA (2005) Sympathetic, sensory, and nonneuronal contributions to the cutaneous vasoconstrictor response to local cooling. Am J Physiol 288(4):H1573-H1579

Kano Y, Padilla DJ, Behnke BJ, Hageman KS, Musch TI, Poole DC (2005) Effects of eccentric exercise on microcirculation and microvascular oxygen pressures in rat spinotrapezius muscle. J Appl Physiol 99(4):1516-1522 
Karunakara RG, Lephart SM, Pincivero DM (1999) Changes in forearm blood flow during single and intermittent cold application. J Orthop Sports Phys Ther 29(3):177-180

Kawaguchi H, Masamoto K, Ito H, Kanno I (2012) Image-based vessel-by-vessel analysis for red blood cell and plasma dynamics with automatic segmentation. Microvasc Res 84(2):178-187. doi:10.1016/j.mvr.2012.05.001

Kayar SR, Banchero N (1985) Sequential perfusion of skeletal muscle capillaries. Microvasc Res 30(3):298-305

Keller DM, Sander M, Stallknecht B, Crandall CG (2010) $\alpha$-Adrenergic vasoconstrictor responsiveness is preserved in the heated human leg. J Physiol 588(Pt19):3799-3808. doi:10.1113/jphysiol.2010.194506

Kindig CA, Richardson TE, Poole DC (2002) Skeletal muscle capillary hemodynamics from rest to contractions: implications for oxygen transfer. J Appl Physiol 92(6):2513-2520

Koganezawa T, Ishikawa T, Fujita Y, Yamashita T, Tajima T, Honda M et al (2006) Local regulation of skin blood flow during cooling involving presynaptic P2 purinoceptors in rats. Br J Pharmacol 148(5):579-586

Lindbom L, Tuma RF, Arfors KE (1980) Influence of oxygen on perfused capillary density and capillary red cell velocity in rabbit skeletal muscle. Microvasc Res 19(2):197-208

Maeda H, Kurose T, Nosaka S, Kawamata S (2014) Microvascular circulation at cool, normal and warm temperatures in rat leg muscles examined by histochemistry using Lycopersicon esculentum lectin. Acta Histochem 116(6):1096-1103. doi:10.1016/j.acthis.2014.05.006

Mazzetti S, Frigerio S, Gelati M, Salmaggi A, Vitellaro-Zuccarello L (2004) Lycopersicon esculentum lectin: an effective and versatile endothelial marker of normal and tumoral blood vessels in the central nervous system. Eur Histochem 48(4):423-428

Minson CT, Berry LT, Joyner MJ (2001) Nitric oxide and neurally mediated regulation of skin blood flow during local heating. J Appl Physiol 91(4):1619-1626

Morikawa S, Baluk P, Kaidoh T, Haskell A, Jain RK, McDonald DM (2002) Abnormalities in pericytes on blood vessels and endothelial sprouts in tumors. Am J Pathol 160(3):985-1000
Musch TI, Terrell JA (1992) Skeletal muscle blood flow abnormalities in rats with a chronic myocardial infarction: rest and exercise. Am J Physiol 262(2 Pt 2):H411-H419

Nakamura-Ishizu A, Morikawa S, Shimizu K, Ezaki T (2008) Characterization of sinusoidal endothelial cells of the liver and bone marrow using an intravital lectin injection method. J Mol Histol 39(5):471-479. doi:10.1007/ s10735-008-9186-x

Nilsson B, Ingvar DH (1967) Intramuscular pressure and contractile strength related to muscle blood flow in man. Scand J Clin Lab Invest Suppl 93:31-38

Poole DC (2014) CrossTalk opposing view: De novo capillary recruitment in healthy muscle is not necessary to explain physiological outcomes. J Physiol 592(Pt 23):5133-5135. doi:10.1113/jphysiol.2014.282145

Poole DC, Copp SW, Ferguson SK, Musch TI (2013) Skeletal muscle capillary function: contemporary observations and novel hypotheses. Exp Physiol 98(12):1645-1658. doi:10.1113/expphysiol.2013.073874

Renkin EM, Gray SD, Dodd LR (1981) Filling of microcirculation in skeletal muscles during timed India ink perfusion. Am J Physiol 241(2):H174-H186

Richardson TE, Kindig CA, Musch TI, Poole DC (2003) Effects of chronic heart failure on skeletal muscle capillary hemodynamics at rest and during contractions. J Appl Physiol 95(3):1055-1062

Robertson RT, Levine ST, Haynes SM, Gutierrez P, Baratta JL, Tan Z et al (2015) Use of labeled tomato lectin for imaging vasculature structures. Histochem Cell Biol 143(2):225-234. doi:10.1007/s00418-014-1301-3

Sakai T, Hosoyamada Y (2013) Are the precapillary sphincters and metarterioles universal componets of the microcirculation? An historical review. J Physiol Sci 63(5):319-331. doi:10.1007/s12576-013-0274-7

Smaje L, Zweifach BW, Intaglietta M (1970) Micropressures and capillary filtration coefficients in single vessels of the cremaster muscle of the rat. Microvasc Res 2(1):96-110

Terjung RL, Engbretson BM (1988) Blood flow to different rat skeletal muscle fiber type sections during isometric contractions in situ. Med Sci Sports Exerc 20(5 Suppl.):S124-S130

\section{Submit your manuscript to a SpringerOpen ${ }^{\circ}$ journal and benefit from:}

- Convenient online submission

- Rigorous peer review

- Immediate publication on acceptance

- Open access: articles freely available online

- High visibility within the field

- Retaining the copyright to your article

Submit your next manuscript at $>$ springeropen.com 